\title{
An Optimised Waste to Energy Incineration Plant and Management Concept
}

\author{
Carl-Arne Pedersen \\ Renova Company, (former GRAAB), Gothenburg, Sweden
}

\section{Treatments and facilities}

More than one (1) million people live in western Sweden. Both at home and in the workplace, residual products are produced which, if not taken care of in the proper manner, would soon grow into large mountains of waste. It is therefore important to use the right methods to treat the waste.

Renova is highly qualified within recycling. environmental protection and waste management. The goal o/the business is not just to recycle/e as much as possible/e. but a/so to the greatest possible/e extent.

Renova has four business areas:

Waste collecting and transports.

Material recycling, biological treatment and disposal.

The handling of hazardous waste materials.

Incineration with energy recovery.

The company has approximately 670 employs and yearly a turnover of 700 millions SEK.

\section{Waste collecting}

Renova collects, transports and treats over 530000 tons of waste and recyclable material 'å year, everything from paper, glass, metal and wood to biological, hazardous and combustible waste. It is all delivered to Renova's plants, where it is recycled or treated in the most appropriate manner. The residual waste which will go to energy recovery is transported in refuse trucks to the Sävenäs waste to energy plant. The waste to be transported longer distances is compacted and loaded from our six transfer stations from small to larger trucks. Transport within the region is thereby de- creased and since some years we also transport burnable waste by train from the north region in western Sweden.

\section{Material recycling, biological treatment and waste disposal}

A large amount of the industrial waste can be recycled either as energy or as raw material. The waste is therefore sorted in Renova's sorting plants, Fläskebo or Sävenäs. After sorting, the material is recovered in manufacturing industries, builders, energy recovery centers and disposal sites to name just a few examples. Much house- hold waste is recyclable and can be utilized as raw material for new products. Newspapers and packaging materials such as sheet metal, glass, 
paper and plastic are left in the recycling containers. Greater amounts of recyclable material or material which cannot be left in the recycling containers may be left at a recycling center.

The inhabitants of Gothenburg can choose between doing their own composting and letting Renova collect the compost. The collected compostable waste is driven to the corn-posting plant in Marieholm for biological treatments. After composting, what was biological waste becomes a clean fertilizer. The composting plant produces different types of soil, which are then used in fields, parks, flower beds and more.

All that remains after material recycling and energy recovery by incineration

Regardless of which methods are used to recycle and treat the waste, something always remains. This is placed in one of Renova's waste disposal sites. Apart from the sludge from the incineration. there is al so other material, which must be disposed of. This may be something which has been sorted out at one of the sorting plants or something which is transported directly to the disposal site, for instance asbestos and other non noncombustible waste.

\section{Handling hazardous waste materials}

Environmentally hazardous waste must be given special treatment. It must therefore be left in separate refuse containers which are found in several places, most often near petrol stations. Ringön is Renova's plant for hazardous waste. It was created to take care of most of the worst waste. The waste is sorted and analyzed at Ringön before it is sent on to environmentally safe final treatment plants.

\section{Incineration with Energy Recovery}

Four hundred thousand tons of waste per year goes to incineration and energy recovery at the Sävenäs waste to energy plant. The Sävenäs plant is today the largest waste to energy plant in Scandinavia. The waste is incinerated at a high temperature and heat from the flue gases will be converted to steam in the waste steam boiler.

The total amount of energy recovered from the plant, incinerating 390000 ton of waste is close to $1200 \mathrm{GWh}$. Produced electricity is yearly $140 \mathrm{GWh}$ and heat production rs yearly $1040 \mathrm{GWh}$

\section{Renova's Environmental policy}

Renova's goal is to offer for sale environmentally friendly services and products in the fields of energy supply, waste handling and recycling. Our customers include building owners, companies and communities in western Sweden. Our services and products shall fulfil our customer's needs while at the same time complying with all governmental regulations and standards. Each Renova employee shall in his or her work show consideration for the environment and contribute to waste reclamation and environmental betterment in the community.

- Lessen the impact of our operations on the environment through the systematic implementation of preventive measures.

- Constantly search for new methods of protecting and improving the environment around us. 
- Comply with present environmental legislation as well as environmental needs and attempt to anticipate those of the future.

- Decrease the use of natural resources, in particular those which e non renewable.

- Require that our subcontractors and suppliers also comply with the stipulations of our environmental policy.

\section{The Sävenäs waste to energy plant}

The plant has three . "von Roll" incineration units. The oldest unit was installed in 1972 and has a capacity of 14 tons of waste. The boiler produces $215^{\circ} \mathrm{C}$ saturated steam at a pressure of 20 bar, (33 MW boiler effect). There are two newer units (in operation since 1994-95 renewal project), each with a capacity of 22 tons of waste (57 MW boiler effect). These two boilers deliver steam at a pressure of 40 bar and a temperature of $400^{\circ} \mathrm{C}$. The thermal system has been dimensioned or an increase in the production of electricity following a new turbine installation. The two new incineration units are connected to the existing wet flue gas cleaning system of two of the three old units, which were replaced in 1994-95.

In the large storage bunker a mix of sorted industrial waste and residual waste from households is stored. The bunker can hold up to 10000 tons of waste, enough for one week's operation with all three furnaces. The waste is feeded into the furnace, where it is incinerated at a temperature of more than $850^{\circ} \mathrm{C}$.

\section{Nox reduction}

Since incineration requires oxygen, air must be added. Two thirds of this air is taken as primary air from the waste bunker, the refuse odour is then "burned up." One third is taken as secondary air from a slag bunker. In addition a part of the flue gas after ESP is returned to the furnace as recycled air. This results in a lower total volume of flue gas after ESP and a decrease in nitrogen oxides. The amount of nitrogen oxides

is al so decreased using the SNCR method with $25 \%$ ammonia/water solution and expanded by low pressure steam injected in three levels by nozzles into the combustion chamber where it reduce nitrogen oxides into nitrogen gas and water. With these de- NOx systems; flue gas recycling (primary method) and SNCR (secondary method) we have reduced the amount of NOx by approximately $85 \%$.

The flue gasses passes through a waste heat boiler for steam generation and further on to flue gas cleaning. An advanced process computer system regulates incineration, air supply and the feeding of waste into the furnaces. This is done to achieve optimal incineration.

After incineration, approximately 20 weight $\%$ of the waste remains as slag. The slag is cooled in a watertight trough before it is collected in the slag bunker. From here it is transported to Renova's land till area in Tagene for separation.

\section{Flue gas cleaning system}

Many hazardous materials found in the waste have collected in the smoke alter incineration. It must therefore be purified. Thanks to flue gas cleaning. the discharge has been reduced to very low levels. 


\section{Electrostatic precipitator (ESP)}

The electrostatic precipitator is the first step in the flue gas cleaning process. More than $99 \%$ of the particles in the flue gases are separated by static electricity .The particles (fly ash), are collected in a silo to be mixed later on with the sludge from the water purification.

\section{Flue gas economizer}

The flue gas supplies heat to the district-heating network through heat transfer in the flue gas economizer. This serves to reduce the temperature of the flue gas from

$230 \mathrm{oC}$ to $140 \mathrm{oC}$, an important step were the heat is converted to district heating network.

\section{The wet scrubbing condense system}

Includes precooler (quench) wash reactor, condensing reactor and re heater. Wash reactor

The primary cleaning takes place in the wash reactor where the flue gases are washed with water. The gas is first cooled in a precooler quench into which water is sprayed to reduce the temperature to $60^{\circ} \mathrm{C}$. The wash reactor has beds containing filler material so that the flue gases are given as much contact surface as possible with the process water which circulates and absorbs pollutants. In the top of the reactor is a drop separator which catches droplets of water where the gas passes. Small particles of dust, hydrochloric acid, hydrofluoric acid, mercury and other heavy metals are dissolved in the water which becomes extremely acidic.

\section{Condensing reactor}

The flue gases are condensed in the condensing reactor, so that the humidity (water vapor) originally from waste is returned to the plant. Through the use of absorption heat pumps, energy is then extracted from the condensed vapor which is again pumped into the top of the condensing reactor and then on to the wash reactor after cooling. In this way through condensing, we produce the scrubbing water we need while, at the same time, raising the plant's total efficiency by more than $16 \%$. The remaining pollutants are now in suspension or dissolved in the process water.

\section{Reheater}

After the flue gas in the condensing reactor it is still saturated with moisture, it would cause the moisture to condense into droplets of water with corrosion in a the stack. Flue gas is therefore reheated to approximately $90^{\circ} \mathrm{C}$, before it passes out through the smokestack.

\section{Fabric filter}

During the autumn of 1999 , the present flue gas cleaning process will be supplemented by a fabric filter after the wet cleaning system.

During a normal operation mode the gas first passes the existing wet cleaning system except for a small portion which by-passes the scrubber stage to provide the $\mathrm{HCI}$ necessary for the sax absorption. The main gas stream from the scrubber and the by- passing gases are mixed at the inlet of a filsorption stage where sorbents are injected and mixed with the gas stream.

The sorbents consists of hydrated lime and fly ash/or activated carbon. The lime reacts with the acid gas components and fly ash, or activated carbon reacts with the dioxin and any mercury in the gas stream forming a solid component which is collected on the bags in fabric filter- 
The clean gas is then extracted by fans and exhausted to atmosphere through existing flue gas fun silencer and stack. The dust is conveyed to a separate silo by a dense phase pneumatic conveying system.

The new filtration stage will al so operate as a gas absorber without the wet stage whereby the gas is first cooled in the economizer to optimal absorption condition before it enters following fabric filter

From the recycled dust silo some fly ash is continuously transported to existing silos where it is stabilized with water sludge before transported to a controlled land fill.

The new filtration stage is designed to meet the new emission requirements also without existing wet system when this is down for service or repair.

\section{Water cleaning system}

The process water from the flue gas cleaning process is extremely acidic and has a $\mathrm{pH}$ $\mathrm{o}$ (approximately 0.5 . The $\mathrm{pH}$ is raised by adding finely ground limestone and hydrated lime.

The remaining ammonia, which was not used during the SNCR reduction of NOx and dissolved in this water will be recovered in the ammonia stripper and reused.

The $\mathrm{pH}$ value is finally adjusted to approximately 9.0 and a precipitating agent, TMTI5, is added which binds the pollutants to sulfide compounds with low solubility.

A flocculation agent, Magnafloc, binds these compounds which are precipitated and sink to the bottom of the separation tank as sludge.

Before final cleaning of the process water in the sand filter, the process water will, from 1999, be cool ed from $55^{\circ} \mathrm{C}$ to $30^{\circ} \mathrm{C}$ through then use of another new absorption heat pump for heat recovery to district heating supply.

Since the water has a salt content of 0.8 percent, it may be safely pumped out in a closed pipeline system into the Göta river, which is also brackish.

Finally, the sludge from the water cleaning is mixed with the fly ash from the electrostatic precipitators. Together they build a residual product "Barnberger cake" which is deposited at a landfill site. Since this residual product is very stable, the leaching of environmentally hazardous materials is prevented.

\section{From waste to electricity and heat}

\section{Production of electricity}

The boiler steam goes to two turbines, one new $35 \mathrm{MW}$ (40 bar steam), one old of $14 \mathrm{MW}$ (20 bar steam).After the turbines, final drainoff, low pressure steam, passes on to the condensers for heat production. If the steam flow exceeds turbine capacity, or when we have a break in turbine operations, the steam can be led directly via reduction valves to the condenser for heat production to the district heating system.

A portion of the total steam flow is led away from the turbines in the form of low pressure steam at 3.5 bar and is used to reheat flue gases and as a steam propellant for the absorption heat pumps. Low-pressure steam at 7 bar is used as expansion steam for the SNCR system for spraying ammonia into the furnace for the reduction of NOx. With all three incinerators in operation, the present p/ant capacity for electrical power is $26 \mathrm{MW}$ Internal needs comprise 6 $\mathrm{MW}$ and the remaining $20 \mathrm{MW}$ can be supplied to the electricity network. The year/y production electricity is today $140 \mathrm{GWh}$. 


\section{Heat supply to the district heating system}

Within Gothenburg's district heating network heated water circulates through some 500 kilometres of pipes and tunnels in a closed system (one of the largest systems for district heating in the world).

In order for Renova to be able to deliver heat to district heating, the waste to energy plant is centrally located in Gothenburg.

The total heat output with al/ three units operated and five heat pumps. is approximately 150 MWh. The year/y production of heat delivered to district heating is around $1000 \mathrm{GWh}$.

To make it possible to continue waste incineration during interruptions in the supply to the district heating systems, steam from waste boilers can be cooled intemal, in water cooling towers.

\section{Absorption heat pumps at the Sävenäs plant}

As far as we know we have the largest installation of absorption heat pumps in the world in our waste to energy p/ant.

In September 1988, four absorption heat pumps (horizontal construction), were installed, each with a nominal cooling capacity of $4.0 \mathrm{MW}$. A new heat pump (vertical construction) with a nominal cooling capacity of $12 \mathrm{MW}$ was in stalled in 1995 in order to our renewal concept.

\section{Operating data for the absorption heat pumps}

The five parallel operating absorption heat pumps are connected to an intermediate cooling System. The heat pumps cool the hot return of intermediate cooling water from flue gas condensation in the evaporator and transport the heat obtained to the absorber and then to district heating network. The total cooling capacity of the five heat pumps operated is $28 \mathrm{MW}$ nominally (maximum $36 \mathrm{MW}$ ).

The absorption heat pumps are ålways operated in a vacuum. The energy used to operate the absorption heat pumps is low pressure steam $(3,5 \mathrm{Bar})$ from the bleedings of turbines. A great amount of negative pressure is needed in the heat pump to achieve evaporation at the prevailing temperature about $40^{\circ} \mathrm{C}$.

Energy optimization, condensing water vapor in flue gases and converted as heat to district heating with absorption heat pumps - "experience and results"

"With our condensing system and heat pumps, energy production have been increased with more than $16 \%$ from the same amount of waste. i.e., approximately $500 \mathrm{kWh}$ more produced energy per ton of waste ".

In one year this means $200 \mathrm{GWh}$ out of a total energy production amounting to $1200 \mathrm{GWh}$. This comes when reducing water vapour in the flue gas from 16 volume $\%$ to 7 volume $\%$. The temperature of the flue gas is thus decreased from $60^{\circ} \mathrm{C}$ to $40^{\circ} \mathrm{C}$.

"Other heat transfer of energy through heat loss and absorption heat pumps"

- Both the turbines' oil lubrication coolant is conducted to the heat pumps intermediate flow for energy recovery.

- The SNCR method propellant steam is conducted to heat pump intermediate flow .A for energy recovery. 
- Condensing water vapor means a decreased flue gas volume by (drier gas) with less intemal electric consumption.

- Condensing water vapor means that the condensed water after energy recovery is to be used for the scrubbing system.

\section{Material advantages}

We have positive experience concerning the material construction and an increased lifetime for iron or stainless steel in the flue gas channels. Due to, the low volume $\%$ of water vapor in the flue gas, after the condensing step. Risks for corrosion is nearly eliminated.

\section{Further advantages}

- The absorption heat pumps have a simple mechanical construction compared to mechanical compressor heat pumps.

- The absorption heat pumps needs only a small amount of electricity compared to mechanical compressor heat pumps.

The absorption heat pumps can be operated almost $100 \%$ of the time yearly as compared to mechanical compressor operated heat pumps who se operation is less than $85 \%$ during a year.

- An environmental advantage is that the absorption heat pumps use water as a cooling agent as compared to compressor operated heat pumps which use freons or ammonia.

- Absorption heat pumps needs only a few hours of maintenance yearly with low costs.

\section{Influence of mercury emissions, results reducing water vapor in flue gas .}

- Flue gas temp. at $60^{\circ} \mathrm{C}, 16$ volume $\%$ vapor is $<25 \mathrm{micrograrn} / \mathrm{m} 3$

- Flue gas temp. decreased to $50^{\circ} \mathrm{C}, 12$ volume $\%$ vapor is $<15 \mathrm{micrograrn} / \mathrm{m} 3$

- Flue gas temp. decreased to $40^{\circ} \mathrm{C}, 8$ volume $\%$ vapor is $<10 \mathrm{microgram} / \mathrm{m} 30$

- Flue gas temp decreased to $33^{\circ} \mathrm{C}, 5-6$ volume $\%$ vapor is $<5 \mathrm{microgram} / \mathrm{m} 3$.

- The mercury input for flue gas before the wet cleaning system were all measured to around $150 \mathrm{microgram} / \mathrm{m} 3$

\section{Emission of dioxin's depend on the flue gas temperature and condensing water vapor}

Flue gas temperature of $60^{\circ} \mathrm{C}$ - $\quad$ Results $<0,50 \mathrm{ng} / \mathrm{m} 3$

Flue gas temperature of $50^{\circ} \mathrm{C}$ - Result $<0,30-0,50 / \mathrm{m} 3$

Flue gas temperature of $40^{\circ} \mathrm{C}-\quad$ Result $<0,20 \mathrm{ng} / \mathrm{m} 3$

Flue gas temperature below $33^{\circ} \mathrm{C}$-Result $<0,10 \mathrm{ng} / \mathrm{m} 3$

\section{The optimal energy utilization of waste with intermediate storage of combustible waste}

- By storing the waste collected during the summer until wintertime we are able to, utilize it as a source of energy during a period when it can be substituted for large quantities of fossil fuel (oil, coal, natural gas). This gives us definite environmental and economic benefits.

- Renova's waste incineration and production planning follows the need and the demand for district heating and electricity. 
- During the winter season from November to April all three incineration units are in operation and deliver approximately 10-12 GWh of electricity and 90-100 GWh of district heating a month. During this time we incinerate 35-40000 tons of household waste and sorted bulk waste a month.

- During spring, (May) and autumn (September/October) we normally only operate two units as the third has been stopped for planned maintenance. During this time we deliver 6-7 GWh of electricity and $65-80 \mathrm{GWh}$ of district heating a month which is 25-30 000 tons of incinerated waste a month.

- During June-August, our main maintenance period, we reduce our production even more and deliver 3-4 GWh of electricity a month and $45-55 \mathrm{GWh}$ of district heating which is 20-24 000 tons of incinerated waste a month.

- In order to accomplish this we must store waste collected during the summer, to be incinerated for the production of energy during the winter.

\section{Waste baling}

The baling process will not be explained here but each bale of waste weighs on the average between 7-800 kg and bales are produced at a speed of 3-4 minutes per bale. Each bale is covered with a few mm of polyethene plastic. I 200-1 800 bales are produced a week. During the 1995-96 we produced approximately 20000 bales and during 1996-98 approximately 28000 bales. For next winter season (1999-2000) we plan to have a supply of between 30-40000 bales.

\section{Summing up our baling experiences 1994-98.}

- We will primarily be baling compacted material.

- Baling minimizes the risk for fires on landfill storage compared with conventional waste storage methods in landfill.

- The polyethene plastic which cover the bale has caused no environmental problems.

- After six months and up to a few years' storage, the bales are still in fresh condition, in the oxygen free environment, their contents have been subjected to neither an anaerobic or aerobic process.

- Since the demand for district heating is low during the summer, this is when we perform maintenance on the boilers. If we hadn't baled waste during this period, we would not have been able to keep three boilers in continuous operation during the winter, in part because the supply of waste wouldn't have been sufficient and in part because we would have been forced to perform maintenance during the winter. We have profited from the experience of previous years when we baled household waste which, not only have a lower energy value, but resulted in flocks of birds descending on the storage depot and the spread of a nauseous stench during the baling process, factors which had a negative influence on the environment.

\section{Environmental advantages}

Some $85 \%$ of the baled material can be considered as biofuel which only causes a marginal increase in $\mathrm{CO} 2$ compared with the fuels it replaces during the cold period; which is, fossils, oil coal and gas. Waste incineration actually then reduce the green-house effect compared with fossil fuels. 


\section{ECOLOGICAL TECHNOLOGY AND MANAGEMENT}

KALMAR, SWEDEN, September 22-24, 1999

\section{Economic effects of baling}

The waste we bale during the summer must meet very stringent requirements. It should be as pure as possible and should have the highest possible energy value, (approximately 4.0 $\mathrm{MWh} / \mathrm{ton}$ ). Baling sorted, compacted industrial, building and demolition waste to be incinerated during the winter results in higher productivity per ton and, of course, increases our earnings.

\section{Management concept and conclusions for the Renova waste to energy plant \\ " Business activities and management"}

Through the incineration of sorted waste, Renova sha/l produce and sell electricity and heating in such a manner that:

- Our customers will be offered waste recycling and energy, which will increase their competitiveness.

- Other business areas within the company can be conducted in a smoothly running, efficient and environmentally friendly manner.

\section{Strategies:}

Within the framework of Renovas strategy which comprises

\section{"Total solutions partnership and quality"}

Renova will make every effort to ensure that the following benefits are available to our customers and other Renova business areas:

- Availability

- Delivery reliability

- Environmentally safe technology

Availability requires not only a high level of performance but also requires that we operate and maintain our incineration units in a safe and efficient manner.

Delivery reliability means that both waste suppliers and energy recipients are guar-anteed that our operations will be free from interruptions.

Environmentally safe technology requires availability, development and the optimization of combustion and flue gas cleaning in order to meet and even exceed the requirements of environmental agencies and other governmental bodies.

Renova's aim is to continuously develop and improve waste management.

This means that recycling and the reuse of different materials is increased and that the amount of environmentally hazardous materials in the waste is reduced. It also means that waste production must be minimized from the start.

The most environmentally friendly waste management is achieved through a combination of different methods.

The go al is that all waste will be source separated and that each fraction will receive the most suitable treatment. 
A crucial aspect of all types of recycling and was te management is the effort made by the individual.

To minimize the amount of waste by reuse, recycle and presort or never produce it.

To do "Life studies" of all products and articles.

When reusing packaging and avoiding products which are hazardous to the environment, we can all contribute to a better environment. 


\section{Renova}

Waste to Eneergy- plant.

Production of ennergy, Waste incineration, 1998.

Total productionn of energy per ton of waste:

$1152434 \mathrm{MWh} / / 280347$ ton

$=3,03 \mathrm{MWh} /$ tonn

Divided in:

\begin{tabular}{llcc}
$\begin{array}{l}\text { Energy productionn } \\
\text { in Steam-boiler: }\end{array}$ & MWh & MWh/ton & Percentage \\
$\begin{array}{l}\text { (Energy of steam) ) } \\
\text { (E98 } 600\end{array}$ & 2,36 & $78 \%$ \\
$\begin{array}{l}\text { Energy productionn } \\
\begin{array}{l}\text { Flue-gas economizizer } \\
64850\end{array}\end{array}$ & 0,17 & $6 \%$ \\
$\begin{array}{l}\text { Energy productionn } \\
\text { in Absorption } \\
\text { Heat-pumps }\end{array}$ & 188984 & 0,50 & $16 \%$ \\
& 1152434 & 3,03 & $100 \%$ \\
\hline
\end{tabular}




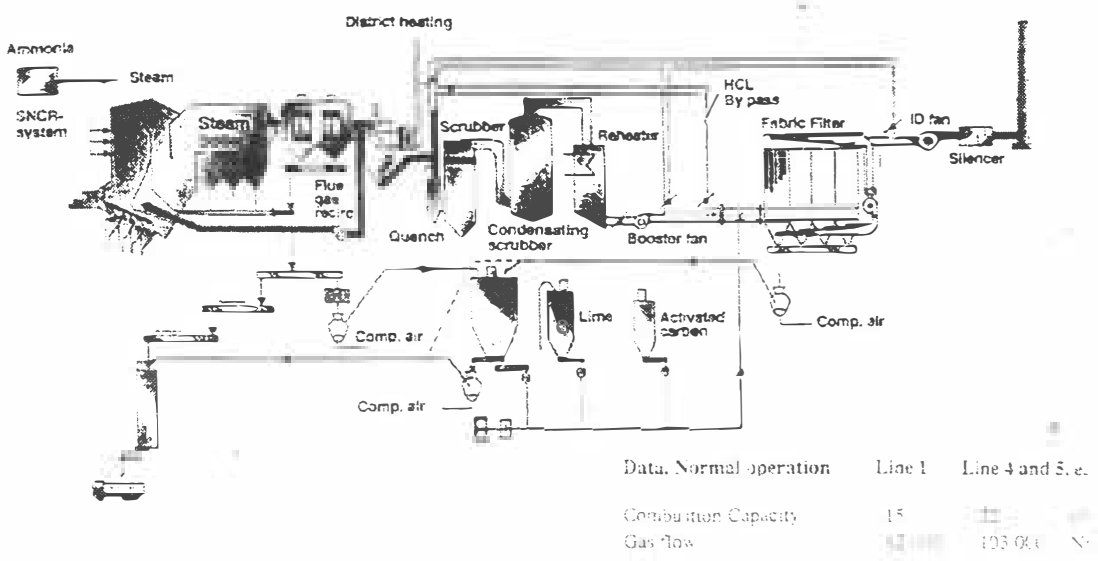

ABB

ABB Environmental Systems $A B$
Fisions

El. requirement in hazardous waste

ABB Guirarit

Dust

iC!

$\mathrm{SC}$.

HF

lis

E⿺辶-

Diner H. II

Diov:n Exur:

gioroduktion \& Siotursiaoolton avia!

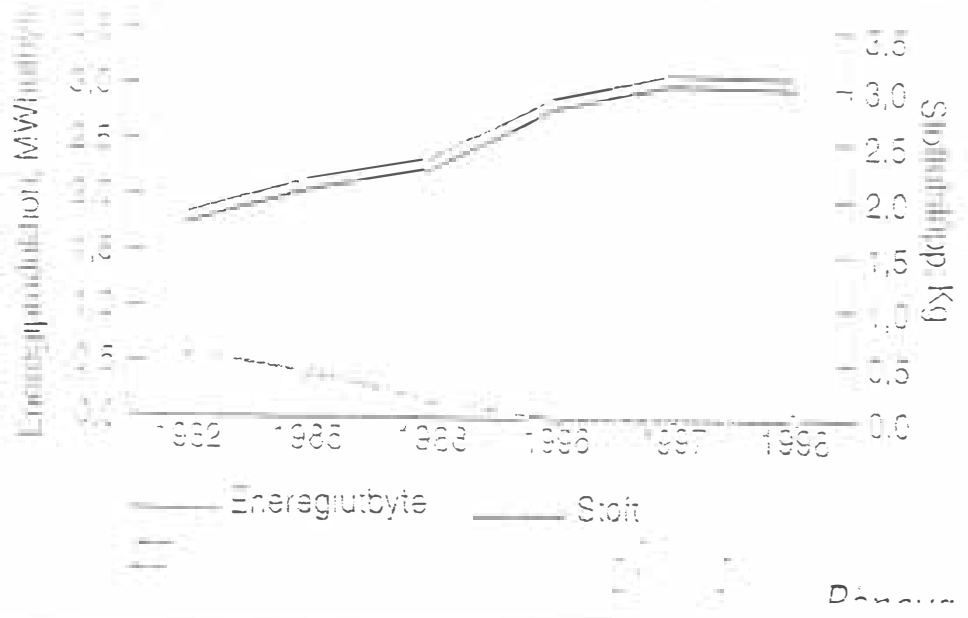

